\title{
Global Patterns of Energy Efficiency of Terrestrial Productivity
}

\author{
Shunji OHTA* \\ 'Department of Human Behavior and Environment Sciences, Faculty of Human Sciences, Waseda University \\ Saitama, 359-1192 Japan
}

\begin{abstract}
This paper describes current patterns of net primary productivity (NPP) and radiation use efficiency (RUE) of terrestrial vegetation of the world. Geographical patterns of NPP showed little productivity in areas with a shortage of climate resources, mainly in high latitudes, high altitudes and arid areas. Potential total net production (TNP) was evaluated to be about $53.2 \times 10^{9} \mathrm{tC}^{\text {year }}{ }^{-1}$ with a total land area of $129.1 \times 10^{8}$ ha excluding Antarctica. Annual shortwave radiation absorbed at the whole terrestrial area has reached $7.2 \times 10^{14} \mathrm{GJ}$. Using this value and the potential TNP in the whole continental area, the world mean of annual RUE in the total for land surface was estimated to be $0.24 \%$. The latitudinal gradient in RUE during the growing period revealed that higher efficiency was in low and high latitudes, which were dominated by tropical rain forests and conifer forests. In contrast, deciduous broad-leaved forests and temperate or tropical grasslands in the mid-latitudes were of efficiency at lower converting the useable solar radiation into biomass, owing mainly to decreased precipitation and the resulting decrease in available water.
\end{abstract}

Key words: Radiation use efficiency, Net primary productivity, Geographical distribution, Terrestrial biome

\section{Introduction}

Plant production is the fixation of solar energy by autotrophs in an ecosystem. Net primary productivity (NPP) is the amount of energy left over after autotrophs have met their own energy needs of respiratory heat. NPP is thus the amount of energy available to all consumer organisms, including humans, and is the beginning of energy flow along the pathways in an ecosystem. Therefore, it is essential to find a global pattern of terrestrial plant energetics that would provide a basis for calculating the productive potential of land areas of the world. Jordan (1971) pointed out that efficiency of wood production increases as amounts of available solar energy decrease, while efficiency of litter production appears to change very little, from analyzing field observation data of 27 communities.

The NPP and the radiation use efficiency (RUE) of primary production, which is defined as a ratio of the energy yield of NPP and the radiation absorbed per unit area of ground in the same time, has long been the subject of research among plant ecologists (Kira, 1976; Uchijima \& Seino, 1987). Golley (1972) has estimated that total net production was about 40.0 $\times 10^{9} \mathrm{tC} \mathrm{year}^{-1}$, and the world RUE of terrestrial vegetation in relationship to annual global solar radiation to be $0.20 \%$. Lieth (1975) has reported that the world mean value of RUE for the land is $0.30 \%$, based on the total NPP value of about $54.9 \times 10^{9} \mathrm{tC}$ year ${ }^{-1}$.

Although the global values of the efficiency of NPP in relationship to total annual solar radiation have been elucidated as mentioned above, little is known about the global distribution of RUE except for some preliminary reports (Uchijima \& Seino, 1987). In this paper, the author attempts to describe the spatial distributions and the latitudinal changes in NPP and RUE using the Chikugo model (Uchijima \& Seino, 1985), climate and vegetation data. The specified RUE value in each major biome and the latitudinal gradient of RUE were estimated for discussion of the relationship between the world biome distributions and the energy use efficiency of net production.

\section{Materials and Methods}

\subsection{Data used for calculation}

All data have a resolution of $0.5^{\circ}$ latitude $\times 0.5^{\circ}$ longitude, interpolated or extrapolated climatologically or geologically if necessary, and they cover all terrestrial land areas excluding Antarctica.

The global climatic data such as mean air temperature, global solar radiation, precipitation, cloud cover, vapor pressure obtained from the IPCC Data Distribution Centre are mean monthly climatology from 1961 to 1990 and have $0.5^{\circ}$ latitude $\times 0.5^{\circ}$ longitude spatial resolutions (New et al., 1999). These data sets cover all terrestrial land excluding Antarctica.

Global $0.5^{\circ} \times 0.5^{\circ}$ land area data was obtained from the CIESIN. The total terrestrial area excluding Antarctica and most of Greenland was $129.1 \times 10^{8}$ ha. The $1^{\circ} \times 1^{\circ}$ resolution seasonal surface albedo data (Matthews, 1983) were interpolated from seasonal to monthly and from $1^{\circ}$ longitude $\times 1^{\circ}$ latitude to $0.5^{\circ}$

Accepted on December 6, 2004 
longitude $\times 0.5^{\circ}$ latitude resolution. 10 minute global altitude data compiled by the U. S. Navy Fleet Numerical Oceanography Center was obtained from GRID-Geneva. The $0.5^{\circ} \times 0.5^{\circ}$ resolution vegetation data set was obtained from the IRL/LDEO Climate Data Library, compiled by Olson et al. (1983). This data set represents the world's Major Ecosystem Complexes ranked by the amounts of carbon in live vegetation and has 44 land ecosystem classes. In this study, the classes were categorized into 12 major biome units (Table 1) to be able to compare easily with previous studies.

\subsection{Calculation of net radiation}

Net radiation, which is the sum of downward short and longwave radiation absorbed by the Earth's surface and upward longwave radiation emitted by the Earth's surface, is the net energy available at the surface. Monthly net radiation $\left(R_{n}, \mathrm{kcal} \mathrm{cm}^{-2}\right)$ was calculated using energy balance equation (Ohta et al., 1993).

$$
R_{n}=(1-\alpha) S_{t}-\sigma T^{4}(0.39-0.058 \sqrt{e}) \times\left(1-c n^{2}\right)
$$

where $\alpha$ is monthly surface albedo (range $0.0-1.0$ ), $S_{t}$ is monthly global solar radiation ( $\mathrm{kcal} \mathrm{cm}$ ), $\sigma$ is the Stefan-Boltzman constant, $T$ is monthly mean air temperature $(\mathrm{K}), e$ is monthly vapor pressure $(\mathrm{mmHg})$, $c$ is proportionality constant, $n$ is cloud amount (range 0.0-1.0). Since albedo data (Matthews, 1983) represents snow free conditions excluding Antarctica and Greenland, $\alpha$ was assumed to equal 0.70 in case $T$ was lower than $0 \mathrm{C}^{\circ}$. $c$ depends on latitude and range between 0.50 at the equator and 0.89 at $90^{\circ}$ North and South (Budyko, 1956). Since downward longwave radiation decreases sharply with an increase in altitude, net radiation at high altitudes (mean altitude over $1500 \mathrm{~m})$ was calculated using correction coefficient $\left(F_{d f}\right)$, which reflects the influence of altitude on downward longwave radiation.

$$
\begin{aligned}
& R_{n}=(1-\alpha) S_{1}- \\
& \left\{\sigma T_{s}^{4}-\sigma T^{4}\left(0.61+0.058 \sqrt{e} \times F_{d f}\right)\right\}\left(1-c n^{2}\right)
\end{aligned}
$$

where $T_{s}$ is surface temperature $(\mathrm{K}) . T_{s}$ was assumed to equal $T-2(\mathrm{~K})$. According to Ohta et al. (1993), correction coefficient $\left(F_{d j}\right)$ was evaluated by

$$
F_{d f}=-0.1742+0.00116 P
$$

where $P$ is atmospheric pressure $(\mathrm{hPa}) . P$ is expressed by the following equation:

$$
P=P_{0}\left(\left(T_{0}-\Gamma z\right) / T_{0}\right)^{(g / R \Gamma)}
$$

where $P_{0}$ is atmospheric pressure at the sea level $(1013.25 \mathrm{hPa}), T_{0}$ is air temperature at $0 \mathrm{~m}(T+\Gamma \mathrm{z}), \Gamma$ is lapse rate $\left(0.006 \mathrm{~K} \mathrm{~m}^{-1}\right), z$ is altitude $(\mathrm{m}), g$ is the acceleration of gravity $\left(9.81 \mathrm{~m} \mathrm{~s}^{-2}\right)$ and $R$ is the gas constant $\left(287 \mathrm{~J} \mathrm{~K}^{-1} \mathrm{~kg}^{-1}\right)$.

\subsection{Calculation of NPP and RUE}

Potential net primary productivity of terrestrial biomes (NPP, t ha ${ }^{-1}$ year $^{-1}$ ) was estimated using the
Chikugo model (Uchijima \& Seino, 1985) with annual net radiation ( $\mathrm{kcal} \mathrm{cm}^{-2}$ ) as described in the previous section.

$$
\mathrm{NPP}=0.29\left(\exp \left(-0.216 \mathrm{RDI}^{2}\right)\right) R_{n}
$$

where RDI is radiative dryness index $\left(=R_{n} / l r\right) . l$ is

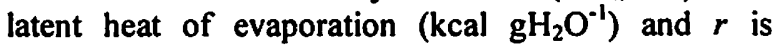
precipitation $(\mathrm{cm})$. Biomass is expressed in units of carbon, assuming that plant biomass is $50 \%$ carbon.

Energy use efficiency, which is called the Lindeman radio, is a ratio of chemical energy created by photosynthesis to absorbed solar energy. Radiation use efficiency (RUE $\mathrm{K}_{\kappa}, \%$ ) based on the NPP and global solar radiation is as follows:

$$
\operatorname{RUE}_{S_{t}}=(\lambda \times \mathrm{NPP}) / S_{t} \times 100
$$

where $\lambda$ is energy content of organic dry matter as seen in Table 1 (kcal $\mathrm{g}^{-1}$, Jordan, 1971; Lieth, 1975), $S_{t}$ is annual global solar radiation $\left(\mathrm{kcal}^{-2}\right)$.

\section{Results and Discussion}

\subsection{Geographical distribution of NPP}

Geographical patterns of NPP showed little productivity in areas with a shortage of climate resources, mainly in high latitudes, high altitudes and arid areas (Fig. 1a). The hyper-arid regions with extremely low NPP of less than $0.5 \mathrm{tC} \mathrm{ha}^{-1}$ year $^{-1}$ lie beneath the subtropical high that is near 20 to 30 degrees in both hemispheres such as the Sahara, Namib Desert and Simpson Desert in Australia. Low NPP areas were also found in high latitudes such as Greenland, the northeast of the Eurasian Continent, northernmost North America, and Ice-cap climates in high altitudes such as the Rocky Mountains, Andes and the Himalayas. The middle latitude belt with relatively plentiful precipitation of Europe, East Asia, and the East coastal regions of North America are covered with temperate forest with NPP-values between 5 to $8 \mathrm{tC} \mathrm{ha}^{-1}$ year $^{-1}$. More than $10 \mathrm{tC} \mathrm{ha}^{-1}$ year $^{-1}$ were found at the equatorial zone with higher temperature and abundant precipitation throughout the year, allowing the growth of evergreen and deciduous broad-leaved forests.

\subsection{Total net production and RUE of the world}

Potential total net production (TNP) was obtained by multiplication of NPP by land area. NPP was evaluated in all terrestrial land excluding Antarctica. The total land area used in calculation of TNP was $129.1 \times 10^{9}$ ha. The potential global net production of terrestrial vegetation was $53.2 \times 10^{9} \mathrm{tC}$ year $^{-1}$ (Table 1). This result agreed well with previous studies (e.g., Lieth, 1975; Saugier et al., 2001) in an acceptable error. Annual global solar radiation absorbed at the whole terrestrial area has reached $7.2 \times 10^{14} \mathrm{GJ}$. Using this value and the potential TNP in the whole continental area, the world mean of annual $\mathrm{RUE}_{\boldsymbol{s},}$ in the total for land surface was estimated to be $0.24 \%$, as 


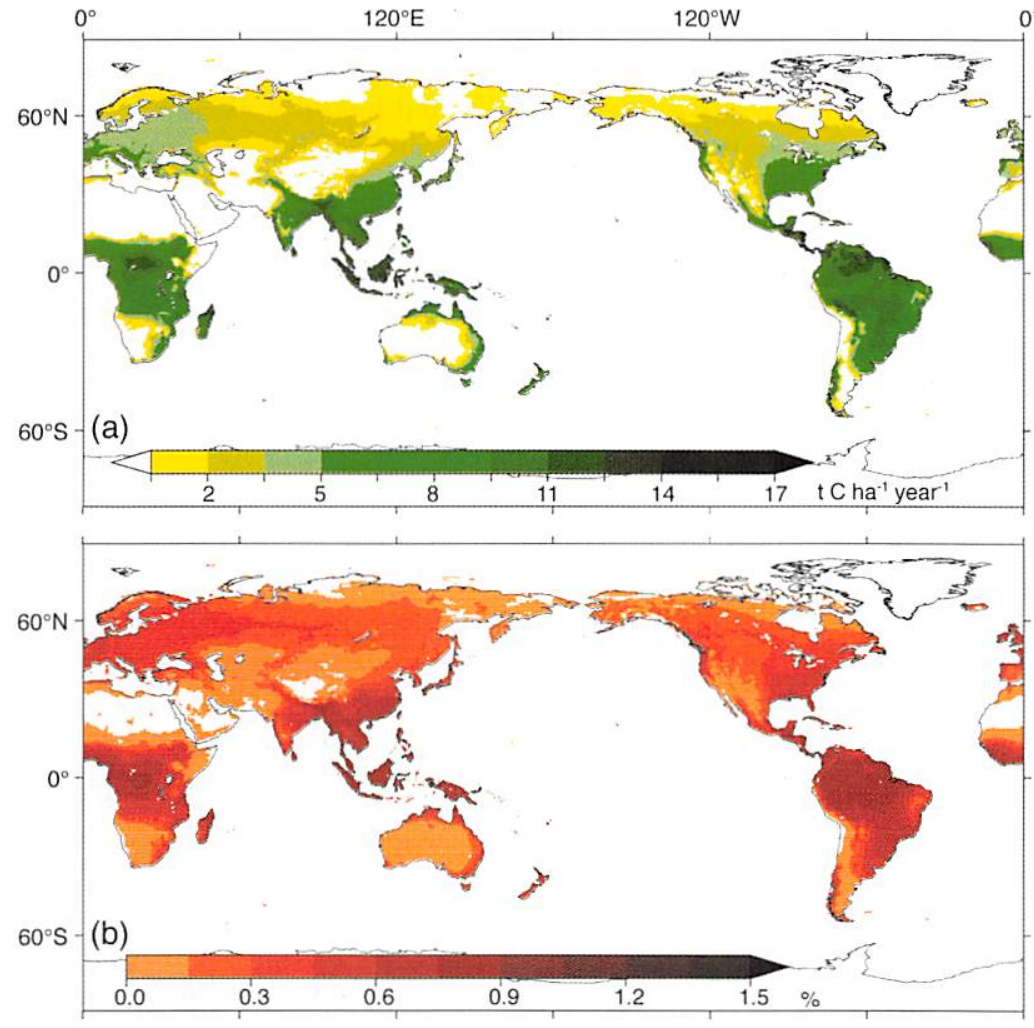

Fig.1 Geographical distribution of net primary productivity (a), and the efficiency of net primary productivity in relationship to total annual global solar radiation (b) of terrestrial vegetation.
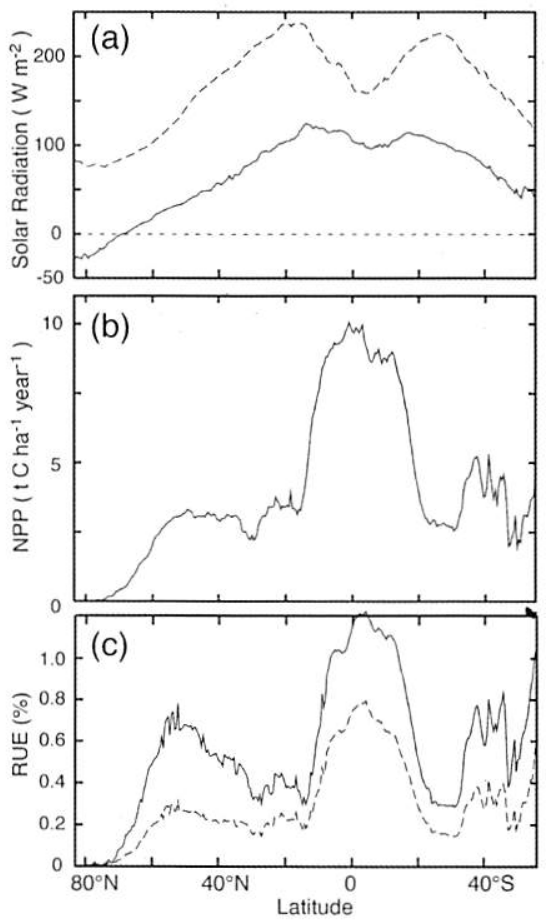

global solar radiation (a- dotted line), net radiation (a- solid line), annual mean of NPP (b), RUE R $_{t}$ (c- dotted line), and $\mathrm{RUE}_{R n>0}(\mathrm{c}$ - solid line) of terrestrial area.

Table 1 Net primary productivity and radiation use efficiency of primary production for each biome.

\begin{tabular}{|c|c|c|c|c|c|c|}
\hline Biome & $\begin{array}{l}\text { Land area } \\
\left(10^{8} \mathrm{ha}\right)\end{array}$ & $\begin{array}{c}\text { Mean } \\
\text { combustion } \\
\text { value } \\
\left(\mathrm{kcal} \mathrm{g}^{-1}\right)\end{array}$ & $\begin{array}{l}\text { Mean NPP } \\
\left(\mathrm{tC} \mathrm{ha}^{-1} \mathrm{yr}^{-1}\right)\end{array}$ & 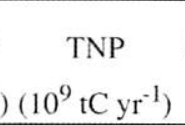 & $\begin{array}{c}\mathrm{RUE}_{S t} \\
(\%)\end{array}$ & $\begin{array}{c}\mathrm{RUE}_{R n>0} \\
(\%)\end{array}$ \\
\hline Tropical rain forest & 11.33 & 4.1 & 10.25 & 11.61 & 0.76 & 1.20 \\
\hline Tropical seasonal forest & 4.66 & 4.2 & 7.46 & 3.48 & 0.46 & 0.83 \\
\hline Temperate evergreen broad-leaved forest & 3.48 & 4.5 & 7.39 & 2.57 & 0.49 & 0.94 \\
\hline Temperate deciduous broad-leaved forest & 4.19 & 4.6 & 5.27 & 2.21 & 0.39 & 0.85 \\
\hline Boreal forest & 16.34 & 4.8 & 2.47 & 4.04 & 0.22 & 0.57 \\
\hline Tundra or alpine tundra & 12.29 & 4.5 & 1.03 & 1.27 & 0.08 & 0.21 \\
\hline Temperate grassland & 21.95 & 4.0 & 3.39 & 7.45 & 0.22 & 0.47 \\
\hline Scrub or shrub & 3.88 & 4.6 & 6.11 & 2.37 & 0.40 & 0.76 \\
\hline Savanna & 14.05 & 4.0 & 4.83 & 6.78 & 0.30 & 0.54 \\
\hline Desert or semi-desert & 17.90 & 4.5 & 0.33 & 0.58 & 0.02 & 0.07 \\
\hline Crop land & 15.12 & 4.1 & 5.59 & 8.44 & 0.37 & 0.74 \\
\hline Others & 2.75 & 4.4 & 6.25 & 1.72 & 0.40 & 0.76 \\
\hline Global & 129.1 & - & - & 53.2 & 0.24 & 0.56 \\
\hline
\end{tabular}

continental area, the world mean of annual $\mathrm{RUE}_{S t}$ in the total for land surface was estimated to be $0.24 \%$, as shown in Table 1. The results coincided very well with estimation values of TNP and RUE $S_{t}$ based on the International Biological Programme (Lieth, 1975).

Figure $1 \mathrm{~b}$ gives the spatial distribution of $\mathrm{RUE}_{S t}$, calculated based on Eq.6. Only a small proportion of annual global solar energy is converted by photosynthesis into plant biomass. Even the most efficient tropical forests can only fix less than $1 \%$ of annual global solar radiation. $\mathrm{RUE}_{S t}$ in arid zones has the lowest efficiency, and is less than $0.1 \%$ of annual shortwave radiation.

\subsection{Biome differences in NPP and RUE}

To evaluate the average NPP and RUE for major vegetation formations, the NPP map (Fig.1a) was superimposed onto a vegetation map proposed by Olson et al. (1983). As seen in Table 1, tropical 
forests occupy about $11 \%$ of land area and about $28 \%$ of global terrestrial TNP, respectively. All forests account for about half of terrestrial TNP, occupying approximately one third of total land. Savannas and temperate grasslands, in contrast, occupy an equivalent area to all forests, and only about $25 \%$ of terrestrial TNP.

$\mathrm{RUE}_{S t}$ ranged from $0.02 \%$ in desert/semi-desert, through $0.39 \%$ in deciduous broad-leaved forests, to $0.76 \%$ in tropical rain forests. To study the RUE in relationship to solar radiation. during the growing season $\left(\mathrm{RUE}_{R n>0}\right)$, the energy efficiency of net production was calculated using monthly net radiation data instead of $S_{f}$ in Eq.6. However, RUE $E_{R n>0}$ was summed up if only monthly net radiation was a positive value. $R_{R E_{R n>0}}$ values in temperate or tropical grasslands were about $0.5 \%$, and those in forests ranged from $0.57 \%$ in boreal forests, through 0.8 to $0.9 \%$ in scrub or shrub and deciduous broadleaved forests, to $1.20 \%$ in tropical rain forests, and the world mean value was $0.56 \%$ (Table 1). The remarkable difference between $R U E_{S t}$ and $R U E_{R n>0}$ is in areas with limited radiation but with sufficient water resources such as tundra and boreal forests. This means that plants at high latitudes and altitudes can intercept light intensively during the short growing period, and there is not so much difference of photosynthetic rate between plant types (Kira, 1976).

\subsection{Latitudinal gradients in NPP and RUE}

As described above, the energy use efficiency of net production changes latitudinally depending on NPP and climates of each latitudinal zone. To indicate distinctly the latitudinal changes in NPP and RUE, these gridded values were summed up in the longitudinal direction and averaged by considering the land area with every 0.5 degree (Fig. 2).

The top of Fig. 2 shows the latitudinal change in annual global solar radiation, and net radiation. Annual solar radiation.generally decreases as latitude increases. A deep trough caused by plentiful rainfall in the equatorial zone divides the two peaks. The latitudinal changes in the NPP (the middle of Fig. 2) and $\mathrm{RUE}_{S t}$ (the bottom of Fig. 2) are completely opposite in phase with those of solar radiations. NPP and $\mathrm{RUE}_{S t}$-curves have a clear peak in the equatorial zone. This trend means that the tropical rain forests in the equatorial zone can more efficiently use the solar energy than the seasonal forests and temperate broadleaved forests in the middle latitudes of both hemispheres. In other words, although plants in midlatitude high pressure zones (approximately $30^{\circ} \mathrm{N}$ and S) have abundant thermal resources, the net production is limited due to water shortages. It is also evident from the bottom of Fig.2 that the $\operatorname{RUE}_{R n>0}$-curve is characterized by three distinct peaks which are divided by two deep troughs. In the peaks, boreal forests are dominated by gymnosperm trees such as spruce, fir, larch and pine, reflecting less available solar radiation and the greater advantage of gymnosperms over angiosperms (Jordan, 1971). There are two reasons that explain why the efficiency of radiation use during the growing period in mid-latitudes is low. First, caloric concentrations of angiosperms are lower than those of gymnosperms. The second reason is that steppes and savannas, which have lower caloric concentrations than trees, occupy as much as three times the forest area in mid-latitudes due to mainly climatic aridity. It is very interested that heavy deforestations and massive human activities have occurred in the mid-latitudes, which have the lower RUE during the growing season.

\section{Acknowledgements}

I am indebted to K. Takishima and M. Naito for their calculation efforts. This study was supported in part by the Ministry of Education, Science and Culture of Japan (a Grant-in-Aid for Scientific Research B15710034) and Waseda University Grant for Special Research Projects (2001A-896, 2002A-580).

\section{References}

Budyko, M. I., 1956: Heat balance at Earth's surface. Gidrometeoizdat, Leningrad, 254pp (in Russian)

Golley, F. B., 1972: Energy flux in ecosystems. Ann. Biol. Colloq., 31, 69-90.

Jordan, C. F., 1971: A world pattern in plants energetics. Am. Sci., 59, 425-433

Kira, T., 1976: Terrestrial ecosystem. Kyoritsushuppan, Tokyo, 166pp. (in Japanese)

Lieth, H., 1975: Primary Production of the major vegetation units of the World. In Productivity of the Biosphere (eds. by Lieth, H., and Whittaker, R. H.). Springer-Verlag, New York, pp. 203-215.

Matthews, E., 1983: Global vegetation and land use: new high resolution data bases for climate studies. $J$. Climate Appl. Meteorol., 22, 474-484.

New, M., Hulme, M., and Jones, P., 1999: Representing twentieth-century space-time climate variability. J. Clim., 12, 829-856.

Ohta, S., Uchijima, Z., and Oshima, Y., 1993: Probable effects of $\mathrm{CO}_{2}$-induced climatic changes on net primary productivity of terrestrial vegetation in East Asia. Ecol. Res., 8, 199-213.

Olson, J. S., Watts,. J. A., and Allison, L. J., 1983: Carbon in living vegetation of major world ecosystems. Oak Ridge National Lab., TN, 151pp.

Saugier, B., Roy, J., and Mooney, H. A., 2001: Estimations of global terrestrial productivity: Converging toward a single number? In Terrestrial Global Productivity (eds. by Roy, J., Saugier, B., and Mooney, H. A.). Academic Press, San Diego, CA, pp. 543-557.

Uchijima, Z., and Seino, H., 1985: Agroclimatic evaluation of net primary productivity of natural vegetation. J. Agric. Meteorol., 40, 343-352. 